\title{
Effect of Silicate Ions on Conversion of Ferric Hydroxide to $\beta$-FeOOH and $\alpha-\mathrm{Fe}_{2} \mathrm{O}_{3}$
}

\author{
Sang-Koo Kwon ${ }^{1, * 1}$, Ken'ichi Kimijima ${ }^{1}$, Kiyoshi Kanie ${ }^{1}$, Atsushi Muramatsu ${ }^{1, * 2}$, \\ Shigeru Suzuki ${ }^{1}$, Eiichiro Matsubara ${ }^{2}$ and Yoshio Waseda ${ }^{1}$ \\ ${ }^{1}$ Institute of Multidisciplinary Research for Advanced Materials, Tohoku University, Sendai 980-8577, Japan \\ ${ }^{2}$ Institute for Materials Research, Tohoku University, Sendai 980-8577, Japan
}

\begin{abstract}
Ferric hydroxide $\left(\mathrm{Fe}(\mathrm{OH})_{3}\right)$ gel, prepared from $\mathrm{FeCl}_{3}$ and $\mathrm{NaOH}$ solutions, was aged at $100^{\circ} \mathrm{C}$ in the presence and absence of silicate ions to examine the effect of silicate ions on the conversion process of condensed $\mathrm{Fe}(\mathrm{OH})_{3}$ gel to iron oxides. The aged suspensions containing colloidal particles in each stage were separated into solid particles and supernatant solutions by centrifugation. X-ray diffraction measurements and transmission electron microscopic observations of the solid particles revealed that $\beta$ - $\mathrm{FeOOH}$ was formed from the $\mathrm{Fe}(\mathrm{OH})_{3}$ gel and subsequently converted into $\alpha-\mathrm{Fe}_{2} \mathrm{O}_{3}$, and the addition of silicate ions in the $\mathrm{Fe}(\mathrm{OH})_{3}$ gel decreased the conversion rate to $\beta$-FeOOH and $\alpha$ $\mathrm{Fe}_{2} \mathrm{O}_{3}$ particles. IR measurements of the solid particles and inductively coupled plasma analyses of the supernatant solutions showed that the adsorption of silicate ions on specific plane of the solid particles was decisive factor for the suppression of the conversion process.
\end{abstract}

(Received October 27, 2004; Accepted December 13, 2004)

Keywords: ferric oxyhydroxide, akaganeite, hematite, silicate ion, fine particle, gel

\section{Introduction}

Corrosion products formed on steel surfaces consist mainly of ferric hydroxides, oxyhydroxides, and oxides. The corrosion rate of the steel substrates is strongly affected by these products formed during the atmospheric corrosion processes. Therefore, their structural and morphological control would be lead to the design and development of corrosion-resistant steels. ${ }^{1,2)}$ The structure of the corrosion products are correlated with the linkages of the local structure, which is fundamentally described by $\mathrm{FeO}_{6}$ octahedral structural units. $\left.{ }^{1,3}\right)$ The $\mathrm{FeO}_{6}$ units are maintained even in the amorphous state of ferric hydroxide $\left(\mathrm{Fe}(\mathrm{OH})_{3}\right){ }^{4)}$ However, their formation mechanism by way of olation and oxolation of the $\mathrm{FeO}_{6}$ units seems as very complicated, because the constitution of the corrosion products is readily changed by various cations and anions contaminated from alloying elements and/or atmospheric exposure. Furthermore, their structure is also influenced by the atmospheric conditions such as temperature and wetting and drying. ${ }^{1)}$ Thus, their synthesis under the well-defined aqueous solution systems and the characterization of the resulting products are required for the investigation of the corrosion mechanism.

Ferric oxyhydroxides $(\mathrm{FeOOH})$ are main components of the corrosion products. Akaganeite $(\beta-\mathrm{FeOOH})$, which can be dehydrated and/or dehydroxylated to ferric oxides $\left(\mathrm{Fe}_{2} \mathrm{O}_{3}\right)$, is one of the polymorphs of $\mathrm{FeOOH} . \beta-\mathrm{FeOOH}$ is known to be formed by hydrolysis of $\mathrm{Fe}^{3+}$ species in aqueous media, and $\beta-\mathrm{FeOOH}$ is considered to be the most detrimental to corrosion-resistance of steel because it contains chloride ions $\left(\mathrm{Cl}^{-}\right){ }^{1,2)}$ Recently, effects of cations and anions on the formation of $\beta$-FeOOH particles followed by the conversion to $\alpha-\mathrm{Fe}_{2} \mathrm{O}_{3}$ particles have been focused. Some elements have been found to strongly influence the formation, structure, and morphology of the $\beta$-FeOOH and $\alpha$ $\mathrm{Fe}_{2} \mathrm{O}_{3}$ particles in aqueous solution systems. ${ }^{5-7)}$ However,

\footnotetext{
${ }^{* 1}$ Graduate Student, Tohoku University

${ }^{* 2}$ Corresponding author, E-mail: mura@tagen.tohoku.ac.jp
}

further experimental studies about the effects of cations and anions on the formation of the corrosion products are essential for the investigation of the corrosion processes.

Silicon ( $\mathrm{Si}$ ) is one of the most important elements of steel and often used as an alloying element so as to improve their corrosion resistance. ${ }^{8-10)}$ Silicate ions are formed by oxidation of silicon contained in steel during atmospheric corrosion. However, the influence of silicate ions on the formation of $\mathrm{FeOOH}$ is still unclear. These backgrounds prompt us to study the effect of silicate ions on the conversion processes of $\mathrm{Fe}(\mathrm{OH})_{3}$ to $\beta-\mathrm{FeOOH}$ and $\alpha-\mathrm{Fe}_{2} \mathrm{O}_{3}$. In this work, the structure and morphology of solid particles, formed during the conversion processes of $\mathrm{Fe}(\mathrm{OH})_{3}$ in the presence and absence of silicate ions, will be characterized. The adsorption behavior of silicate ions will be also examined.

\section{Experimental}

Reagent-grade ferric chloride hexahydrate $\left(\mathrm{FeCl}_{3} \cdot 6 \mathrm{H}_{2} \mathrm{O}\right)$, sodium hydroxide aqueous solution $\left(10 \mathrm{~mol} \mathrm{dm}^{-3}\right)$, and sodium orthosilicate $n$-hydrate $\left(\mathrm{Na}_{4} \mathrm{SiO}_{4} \cdot n \mathrm{H}_{2} \mathrm{O} \quad(n=3.4\right.$ determined by ICP measurement)) were used as received. The method to prepare $\beta$-FeOOH and $\alpha-\mathrm{Fe}_{2} \mathrm{O}_{3}$ particles was fundamentally identical to the previous one. ${ }^{11-15)}$ The $\mathrm{FeCl}_{3}$ solution was filtered through $0.20 \mu \mathrm{m}$ millipore filter to remove insoluble particulates. Aqueous $\mathrm{NaOH}$ solution $\left(5.4 \mathrm{~mol} \mathrm{dm}^{-3}\right)$ was added to $2.0 \mathrm{~mol} \mathrm{dm}^{-3} \mathrm{FeCl}_{3}$ aqueous solution containing $\mathrm{Na}_{4} \mathrm{SiO}_{4} \cdot n \mathrm{H}_{2} \mathrm{O}(n=3.4)$ more than $10 \mathrm{~min}$ at $0^{\circ} \mathrm{C}$ under agitation $(300 \mathrm{rpm})$ to make initial $\mathrm{pH}$ of $\mathrm{Fe}(\mathrm{OH})_{3}$ gel fixed value ranged 4.8 to 5.2 since the addition of silicate ions was found to increase $\mathrm{pH}$ of the resulting gels. ${ }^{16)}$ The concentration of silicate ions was adjusted to be $0,0.050$, and $0.100 \mathrm{~mol} \mathrm{dm}^{-3}$, which was corresponding to $0,5.0$, and $10.0 \mathrm{~mol} \%$ based on the ferric ions, respectively. The highly viscous $1.0 \mathrm{~mol} \mathrm{dm}^{-3} \mathrm{Fe}(\mathrm{OH})_{3}$ gel was formed through these processes, and then aged at $100^{\circ} \mathrm{C}$ for different time from $4 \mathrm{~h}$ to 14 days, in order to study influence of silicate ions on the conversion processes of the $\mathrm{Fe}(\mathrm{OH})_{3}$ gel to the $\beta$-FeOOH and $\alpha-\mathrm{Fe}_{2} \mathrm{O}_{3}$ particles. After a 
given aging time, the suspension was cooled to room temperature by running water. Solid particles were washed with the combination of centrifugation of $18000 \mathrm{rpm}$ for $30 \mathrm{~min}$ and dispersion with doubly distilled and deionized water for two times, and then freeze-dried.

The crystallographic structures of the obtained solid particle samples were identified by Rigaku RAD-B RINT 2000 system using $\mathrm{Ni}$-filtered $\mathrm{Cu} \mathrm{K} \alpha$ irradiation $(36 \mathrm{kV}$, $20 \mathrm{~mA}$ ). Morphologies of the solid particles were observed by using a transmission electron microscope, JEOL JEM1200EX II with an acceleration voltage of $60 \mathrm{kV}$. The $\mathrm{pH}$ value of the supernatant solution separated from the suspension was recorded with TOA DKK pH meter HM60G. Inductively coupled plasma (ICP) equipment, PerkinElmer Optima 3300, was used to examine concentration of ferric and silicate ions in the supernatant solutions.

\section{Results and Discussion}

\subsection{The conversion of $\mathrm{Fe}(\mathrm{OH})_{3}$ by aging at $100^{\circ} \mathrm{C}$}

$\mathrm{Fe}(\mathrm{OH})_{3}$ suspensions with $0,0.050$, and $0.100 \mathrm{~mol} \mathrm{dm}^{-3}$ $\mathrm{Na}_{4} \mathrm{SiO}_{4}$ were aged at $100^{\circ} \mathrm{C}$ for periods from $4 \mathrm{~h}$ to 14 days. Figure 1(a) shows the XRD patterns of the solid particles separated from the aged suspensions without $\mathrm{Na}_{4} \mathrm{SiO}_{4}$. The aging periods are $4 \mathrm{~h}, 6 \mathrm{~h}, 24 \mathrm{~h}$, and 14 days, respectively. These patterns indicate that $\beta$-FeOOH particles are formed from the $\mathrm{Fe}(\mathrm{OH})_{3}$ gel by aging for $4 \mathrm{~h}$, but the line broadening of the diffraction peaks suggests that they are poorly crystalline. The $\beta$-FeOOH particles started to be

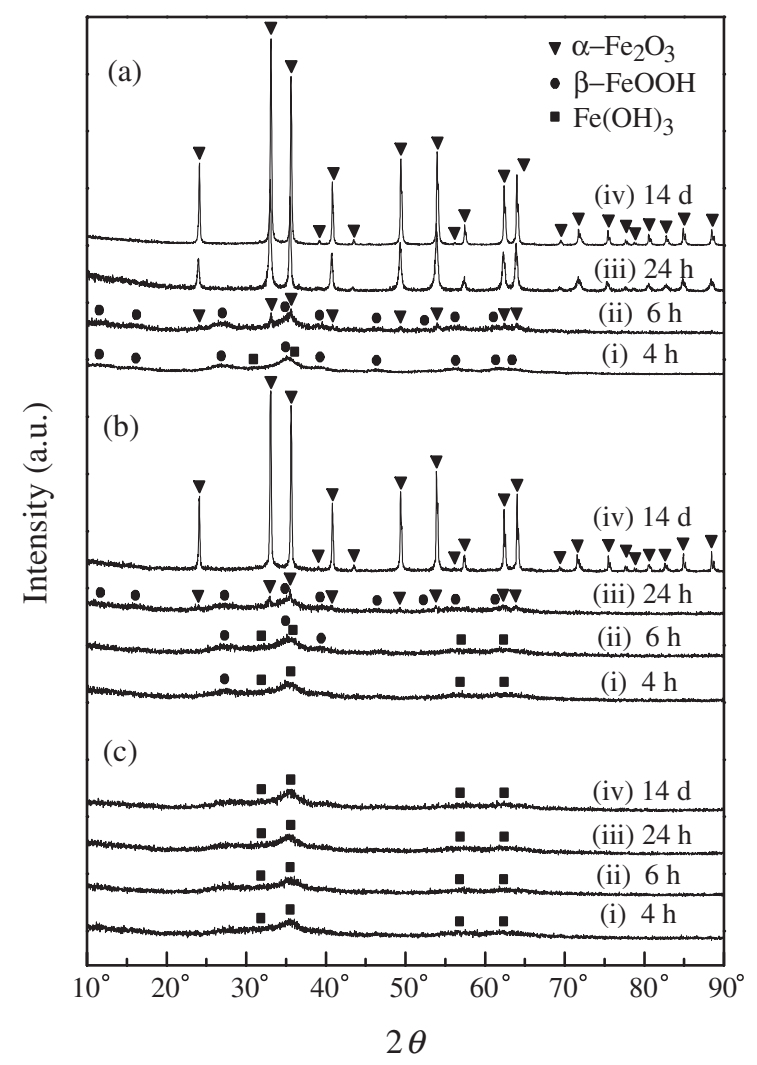

Fig. 1 XRD patterns of solid particles during the conversion process from $1.0 \mathrm{~mol} \mathrm{dm}^{-3} \mathrm{Fe}(\mathrm{OH})_{3}$ gel to $\beta-\mathrm{FeOOH}$ and $\alpha-\mathrm{Fe}_{2} \mathrm{O}_{3}$ particles with (a) 0 , (b) 0.050 , and (c) $0.100 \mathrm{~mol} \mathrm{dm}^{-3} \mathrm{Na}_{4} \mathrm{SiO}_{4}$ aged at $100^{\circ} \mathrm{C}$ for (i) $4 \mathrm{~h}$, (ii) $6 \mathrm{~h}$, (iii) $24 \mathrm{~h}$, and (iv) 14 days. converted to $\alpha-\mathrm{Fe}_{2} \mathrm{O}_{3}$ particles by aging for $6 \mathrm{~h}$. All diffraction peaks of the solid particles aged for $24 \mathrm{~h}$ are assigned as the $\alpha-\mathrm{Fe}_{2} \mathrm{O}_{3}$ structure, indicating the complete conversion to $\alpha-\mathrm{Fe}_{2} \mathrm{O}_{3}$.

In the presence of $0.050 \mathrm{~mol} \mathrm{dm}^{-3} \mathrm{Na}_{4} \mathrm{SiO}_{4}$, XRD profiles of the solid particles show that the conversion from the $\mathrm{Fe}(\mathrm{OH})_{3}$ gel to the $\beta$-FeOOH particles is remarkably suppressed by the addition of silicate ions, as shown in Fig. 1(b). $\alpha-\mathrm{Fe}_{2} \mathrm{O}_{3}$ particles converted from $\beta$-FeOOH particles, which are observed by aging for $6 \mathrm{~h}$ in the absence of silicate ions, emerge by aging for $24 \mathrm{~h}$ in the presence of silicate ions. The $\beta$-FeOOH particles are converted to the $\alpha-\mathrm{Fe}_{2} \mathrm{O}_{3}$ particles completely by aging for 14 days. Remarkable difference of structural changes by the addition of silicate ions is observed in the solid particles with $0.100 \mathrm{moldm}^{-3} \mathrm{Na}_{4} \mathrm{SiO}_{4}$, as revealed in Fig. 1(c). The conversion of the $\mathrm{Fe}(\mathrm{OH})_{3}$ gel to the $\beta$-FeOOH and $\alpha-\mathrm{Fe}_{2} \mathrm{O}_{3}$ particles is completely suppressed by silicate ions increased to $0.100 \mathrm{~mol} \mathrm{dm}^{-3}$, although the XRD intensity is slightly increased with aging time. Any diffraction peaks of $\beta$-FeOOH and $\alpha-\mathrm{Fe}_{2} \mathrm{O}_{3}$ are not detected and line broadening of the diffraction peaks indicates that they are poorly crystalline like amorphous phase.

The morphological changes of the solid particles with aging time were observed by TEM to compare the structural results obtained by XRD with the morphology of the solid particles. Figure 2 shows TEM micrographs of the solid particles obtained in the presence of $0,0.050$, and 0.100 mol dm ${ }^{-3} \mathrm{Na}_{4} \mathrm{SiO}_{4}$. The TEM micrographs of the particles without silicate ions (Fig. 2(a)) aged for $6 \mathrm{~h}$ exhibit pseudocubic $\alpha-\mathrm{Fe}_{2} \mathrm{O}_{3}$ particles of black contrast start to be formed actively like the XRD profiles. The solid particles aged for $24 \mathrm{~h}$ consist of only $\alpha-\mathrm{Fe}_{2} \mathrm{O}_{3}$ particles about $200 \mathrm{~nm}$ in diameter in accordance with the results of XRD profiles. On the other hand, the formation of the $\alpha-\mathrm{Fe}_{2} \mathrm{O}_{3}$ particles is initiated by aging for $24 \mathrm{~h}$ and finished by aging for 14 day in the presence of $0.050 \mathrm{~mol} \mathrm{dm}^{-3}$ silicate ions. Although the results corresponded to the formation of pseudocubic $\alpha$ - $\mathrm{Fe}_{2} \mathrm{O}_{3}$ particles in previous woks, ${ }^{11,12)}$ the conversion rate to $\alpha-\mathrm{Fe}_{2} \mathrm{O}_{3}$ particles is decreased as silicate ions concentration increased. A remarkable difference is found in the final size and morphology of the solid particles by the addition of silicate ions. Ellipsoidal particles are obtained by aging for $24 \mathrm{~h}$. They grow about $500 \mathrm{~nm}$ in particle long axis in the suspension with $0.050 \mathrm{~mol} \mathrm{dm}^{-3} \mathrm{Na}_{4} \mathrm{SiO}_{4}$ by aging for 14 days, which is larger than the particle size obtained in silicate-free system. They were assigned to the $\alpha-\mathrm{Fe}_{2} \mathrm{O}_{3}$ structure in the XRD patterns. In contrast, $\beta$-FeOOH and $\alpha-\mathrm{Fe}_{2} \mathrm{O}_{3}$ particles are not observed in the suspensions as the concentration of silicate ions increased to $0.100 \mathrm{~mol} \mathrm{dm}^{-3}$ which are aged even after 14 days. Thus, the addition of $0.100 \mathrm{~mol} \mathrm{dm}^{-3}$ silicate ions considerably suppressed the conversion of $\mathrm{Fe}(\mathrm{OH})_{3}$ to $\beta$ FeOOH and $\alpha-\mathrm{Fe}_{2} \mathrm{O}_{3}$. The formation of the ellipsoidal $\alpha$ $\mathrm{Fe}_{2} \mathrm{O}_{3}$ particles by the addition of $0.050 \mathrm{~mol} \mathrm{dm}^{-3}$ can be explained by the specific adsorption of silicate ions on the $\alpha$ $\mathrm{Fe}_{2} \mathrm{O}_{3}$ particles. Such morphological control using anisotropic crystal growth inhibition by the specific adsorption has been observed in previous reports. ${ }^{13,17-19)}$ In the case with $0.100 \mathrm{~mol} \mathrm{dm}^{-3}$ silicate ions, the crystal growth inhibition effect by the adsorption might be strongly suppressed the formation of $\alpha-\mathrm{Fe}_{2} \mathrm{O}_{3}$ particles. 
(a) none
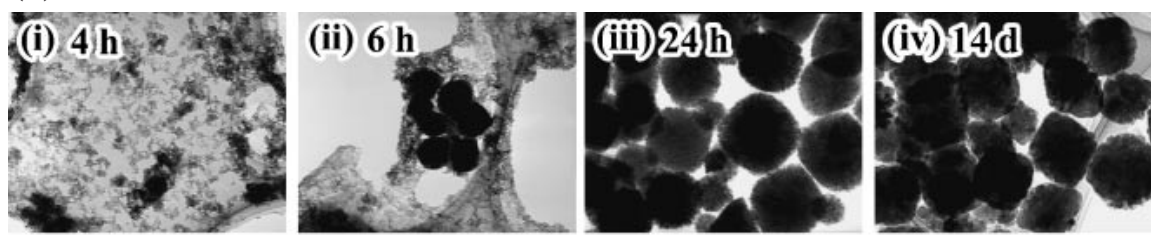

(b) $0.050 \mathrm{~mol} \mathrm{dm}^{-3}$
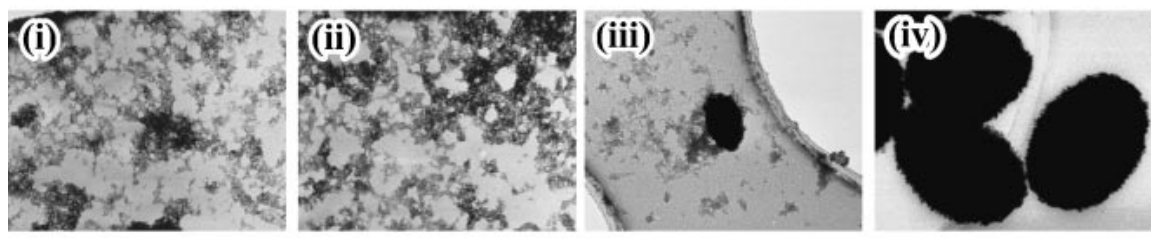

(c) $0.100 \mathrm{~mol} \mathrm{dm}^{-3}$
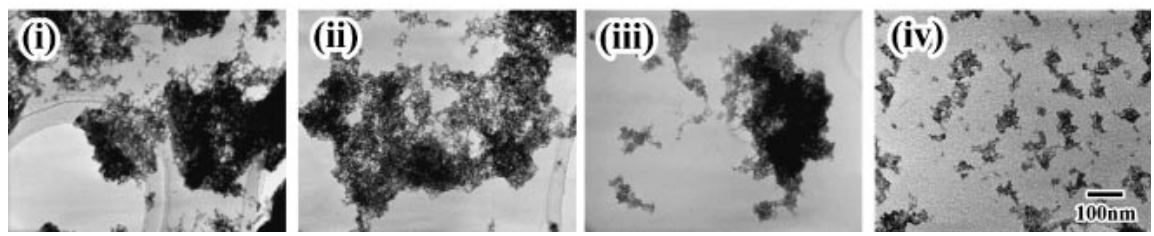

Fig. 2 TEM micrographs of solid particles obtained from the suspension with (a) 0 , (b) 0.050 , (c) $0.100 \mathrm{~mol} \mathrm{dm}^{-3} \mathrm{Na}_{4} \mathrm{SiO}_{4}$ by aging for (i) $4 \mathrm{~h}$, (ii) $6 \mathrm{~h}$, (iii) $24 \mathrm{~h}$, and (iv) 14 days.

\section{2 pH Changes by aging at $100^{\circ} \mathrm{C}$}

In order to obtain information complementary to the formation of the $\beta$ - $\mathrm{FeOOH}$ and $\alpha-\mathrm{Fe}_{2} \mathrm{O}_{3}$ particles in the condensed $\mathrm{Fe}(\mathrm{OH})_{3}$ gel, $\mathrm{pH}$ of the supernatant solutions separated from the aged suspensions of each stage was measured at room temperature. Figure 3 shows the $\mathrm{pH}$ values of the supernatant solution with $0,0.050$, and $0.100 \mathrm{~mol} \mathrm{dm}^{-3}$ silicate ions as a function of the aging time. In the supernatant solution without silicate ions, $\mathrm{pH}$ continues to decrease rapidly from the initial stage to the final stage during the conversion process with increasing aging time. On the other hand, $\mathrm{pH}$ value of the supernatant solutions with 0.050 and $0.100 \mathrm{~mol} \mathrm{dm}^{-3}$ silicate ions increases from 0 to $4 \mathrm{~h}$. For the suspensions with $0.050 \mathrm{~mol} \mathrm{dm}^{-3}$ silicate ions, the rate of $\mathrm{pH}$ decrease is drastically reduced from $0 \mathrm{~h}$ to $12 \mathrm{~h}$ and a subsequent meta-stable stage is observed newly in aging time from about $12 \mathrm{~h}$ to $24 \mathrm{~h}$, in which $\mathrm{Fe}(\mathrm{OH})_{3}$ gel is converted to $\beta$-FeOOH particles. After then, $\mathrm{pH}$ again decreases by aging over $24 \mathrm{~h}$ up to 4 days and a stable stage is observed in aging over 4 days. During the stage with $\mathrm{pH}$ decrease, the $\beta$ FeOOH particles are converted to the $\alpha-\mathrm{Fe}_{2} \mathrm{O}_{3}$ particles, as revealed by XRD measurements. The $\mathrm{pH}$ decrease can be explained by the lower solubility of $\alpha-\mathrm{Fe}_{2} \mathrm{O}_{3}$ than $\mathrm{Fe}(\mathrm{OH})_{3}$ and $\beta-\mathrm{FeOOH}$, that is, the lower solubility products of $\alpha$ $\mathrm{Fe}_{2} \mathrm{O}_{3},\left[\mathrm{Fe}^{3+}\right]\left[\mathrm{OH}^{-}\right]^{3}{ }^{18)}$ Significant $\mathrm{pH}$ changes due to the formation of $\beta$-FeOOH and $\alpha-\mathrm{Fe}_{2} \mathrm{O}_{3}$ are not observed in the supernatant solutions with $0.100 \mathrm{~mol} \mathrm{dm}^{-3}$ silicate ions, as shown in Fig. 3.

\subsection{Changes in the concentrations of iron and silicon species by aging}

Concentrations of iron and silicon species in the supernatant solutions as a function of the aging time are shown in Fig. 4. In any cases, iron species are not detected by ICP analyses in the initial stage, but the concentrations are

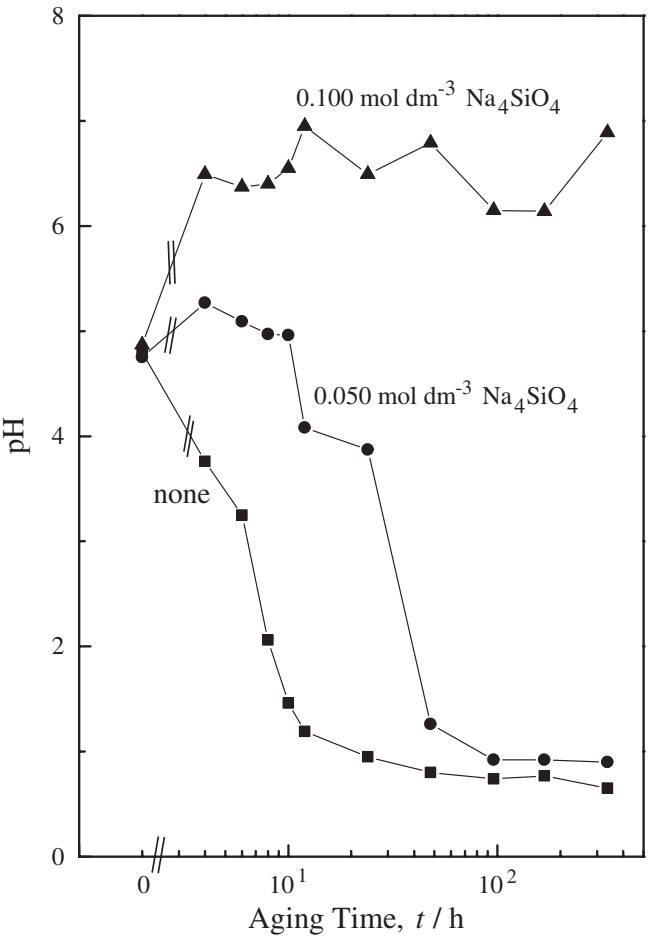

Fig. 3 Changes in $\mathrm{pH}$ of the solution in the suspension with $0,0.050$, and $0.100 \mathrm{~mol} \mathrm{dm}^{-3} \mathrm{Na}_{4} \mathrm{SiO}_{4}$ as a function of aging time at $100^{\circ} \mathrm{C}$.

drastically increased after aging about $6 \mathrm{~h}$ in the absence of silicate ions. It is due to decrease of $\mathrm{pH}$ by the formation of the $\alpha-\mathrm{Fe}_{2} \mathrm{O}_{3}$ particles, as shown in Fig. 3 and Fig. 1(a). The concentration is slightly decreased by further aging at $100^{\circ} \mathrm{C}$, and approached to a steady-state after aging for 4 days. However, the increase in the concentration of iron species by aging is delayed between $24 \mathrm{~h}$ and 2 days by the presence of 


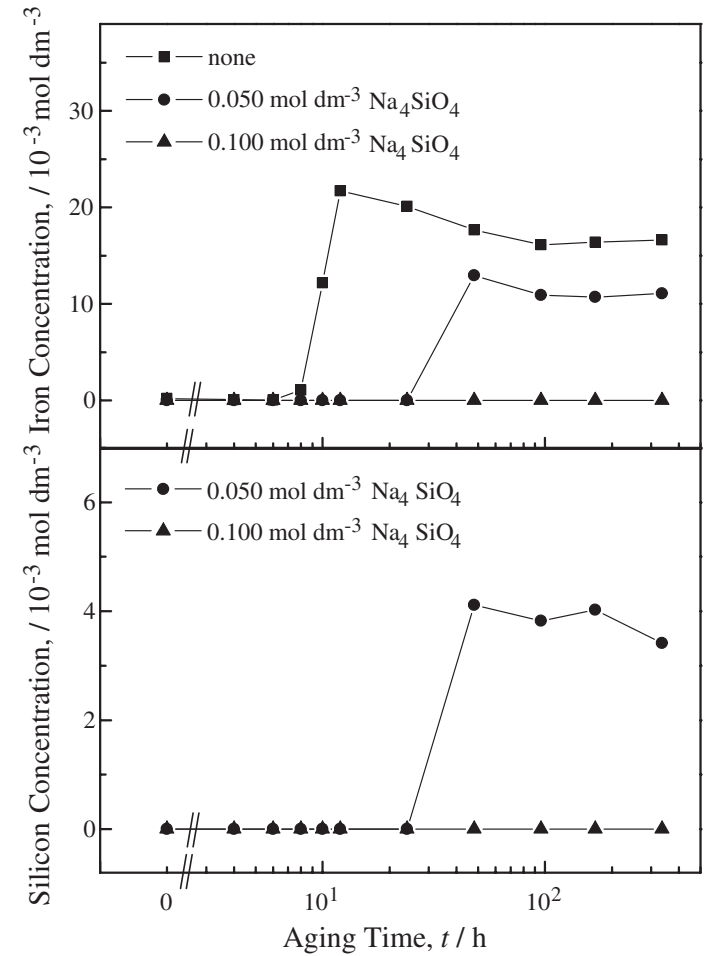

Fig. 4 Changes in concentrations of iron and silicon species in the supernatant solution with $0,0.050$, and $0.100 \mathrm{moldm}^{-3} \mathrm{Na}_{4} \mathrm{SiO}_{4}$ as a function of aging time at $100^{\circ} \mathrm{C}$.

$0.050 \mathrm{~mol} \mathrm{dm}^{-3}$ silicate ions. During this period, conversion from $\beta$-FeOOH to $\alpha-\mathrm{Fe}_{2} \mathrm{O}_{3}$ is observed (Fig. 1(b)). Such increase in the concentration of iron species is not observed in the supernatant solution with $0.100 \mathrm{~mol} \mathrm{dm}^{-3}$ silicate ions.

In the case with $0.050 \mathrm{~mol} \mathrm{dm}^{-3}$ silicate ions, the drastic change of the silicon concentration from 0 to $0.004 \mathrm{~mol} \mathrm{dm}^{-3}$ after aging for about $24 \mathrm{~h}$ is observed. It is corresponding to the formation of the $\alpha-\mathrm{Fe}_{2} \mathrm{O}_{3}$ particles. Silicon species could not be detected in the supernatant solution of the system with $0.100 \mathrm{~mol} \mathrm{dm}^{-3}$ silicate ions. The result indicates that all of the silicate ions added in each system are totally used in the initial stages, regardless of their addition amounts, by the complexation with the $\mathrm{Fe}(\mathrm{OH})_{3}$ gel and/or adsorption on the solid particles. Then, in the case with $0.050 \mathrm{~mol} \mathrm{dm}^{-3}$ silicate ions, less than $10 \%$ silicate ions were released into the supernatant solutions by the formation of the $\alpha-\mathrm{Fe}_{2} \mathrm{O}_{3}$ particles. Silicate adsorption amount on $\beta-\mathrm{FeOOH}$ can be higher than $\alpha-\mathrm{Fe}_{2} \mathrm{O}_{3}$. Thus, the influence of silicate ions can be explained by that the silicate ions suppress the formation of direct precursors of $\beta$-FeOOH and $\alpha-\mathrm{Fe}_{2} \mathrm{O}_{3}$ and/or reduce the formation rate of the particles. On the other hand, IR measurements of the solid particles in the early stages, obtained in the presence of silicate ions, revealed that the silicate ions were adsorbed on the solid surfaces. The absorption amount was increased with increasing the addition amounts of the silicate ions.

In the present study, we have observed that the suppression of the conversion from $\mathrm{Fe}(\mathrm{OH})_{3}$ gel to $\beta$ - $\mathrm{FeOOH}$ and $\alpha$ $\mathrm{Fe}_{2} \mathrm{O}_{3}$ by the addition of the silicate ions in the aqueous solution systems. However, further detailed characterization and evaluation will be needed to understand the role of silicate ions completely.

\section{Conclusions}

Powder XRD, TEM, pH, IR measurements, and ICP analyses have been used for characterizing influences of silicate ions on the conversion of $\mathrm{Fe}(\mathrm{OH})_{3}$ gel to solid particles of $\beta$-FeOOH and $\alpha-\mathrm{Fe}_{2} \mathrm{O}_{3}$ by aging. Main concluding remarks obtained from this work are as follows:

(1) The addition of silicate ions drastically suppressed the conversion of $\mathrm{Fe}(\mathrm{OH})_{3}$ gel to $\beta$ - $\mathrm{FeOOH}$ and $\alpha-\mathrm{Fe}_{2} \mathrm{O}_{3}$ particles and the conversion of $\mathrm{Fe}(\mathrm{OH})_{3}$ gel was not observed in the suspensions as the concentration of silicate ions increased to $0.100 \mathrm{~mol} \mathrm{dm}^{-3}$.

(2) Silicate ions had remarkably strong affinity with ferric ions and this is considered to lead to the inhibition of the conversion process of $\mathrm{Fe}(\mathrm{OH})_{3}$ gel to $\beta$-FeOOH and $\alpha$ $\mathrm{Fe}_{2} \mathrm{O}_{3}$ particles.

\section{Acknowledgements}

The authors would like to express sincere thank to Professor emeritus T. Sugimoto for his kind support and discussion. The authors are also grateful to Mr. K. Sakata for ICP measurements. This work was supported by the Grantin-Aid for Scientific Research Fund from the Japan Society for Promotion of Science (No 15656152).

\section{REFERENCES}

1) C. Leygraf and T. Graedel: Atmospheric Corrosion, (Wiley-Interscience, New York, 2000).

2) R. M. Cornell and U. Schwertmann: The Iron Oxides, (Wiley-VCH, Weinheim, 2003).

3) S. Suzuki, M. Saito, M. Kimura, T. Suzuki, H. Kihira and Y. Waseda: ISIJ Int. 43 (2003) 366-372.

4) K. Shinoda, E. Matsubara, A. Muramatsu and Y. Waseda: Mater. Trans., JIM 35 (1994) 394-398.

5) T. Ishikawa, R. Katoh, A. Yasukawa, K. Kandori, T. Nakayama and F. Yuse: Corros. Sci. 43 (2001) 1727-1738.

6) T. Ishikawa, T. Motoki, R. Katoh, A. Yasukawa, K. Kandori, T. Nakayama and F. Yuse: J. Colloid Interface Sci. 250 (2002) 74-81.

7) K. Kanie, A. Muramatsu, S. Suzuki and Y. Waseda: Mater. Trans. 45 (2004) 968-971.

8) G. H. Kelsall and R. A. Williams: J. Electrochem. Soc. 138 (1991) 931940.

9) U. Wolff, F. Schneider, K. Mummert and L. Schultz: Corrosion 56 (2000) 1195-1201

10) S. Giordana and C. Fiaud: Electrochim. Acta 47 (2002) 1683-1689.

11) Y. Waseda and A. Muramatsu Eds.: Morphology Control of Materials and Nanoparticles, (Springer, Berlin, 2003).

12) T. Sugimoto, M. M. Kahn, K. Sakata, A. Muramatsu and H. Itoh: Colloids Surf. A 79 (1993) 233-247.

13) T. Sugimoto, Y. Wang, H. Itoh and A. Muramatsu: Colloids Surf. A 134 (1998) 265-279.

14) T. Sugimoto and Y. Wang: J. Colloid Interface Sci. 207 (1998) 137149.

15) D. Shindo, G.-S. Park, Y. Waseda and T. Sugimoto: J. Colloid Interface Sci. 168 (1994) 478-484.

16) S. K. Kwon, K. Kimijima, K. Kanie, A. Muramatsu, S. Suzuki, E. Matsubara and Y. Waseda: ISIJ Int. 45 (2005) 77-81.

17) T. Sugimoto, S. Waki, H. Itoh and A. Muramatsu: Colloids Surf. A 109 (1996) 155-165

18) T. Sugimoto and A. Muramatsu: J. Colloid Interface Sci. 184 (1996) 626-638.

19) H. Itoh and T. Sugimoto: J. Colloid Interface Sci. 265 (2003) 283-295. 